\title{
Pandemi Sürecinde Tüketicilerde Hissedilen Ölüm Kaygısının Demografik Faktörlere Göre Değerlendirilmesi
}

\section{Evaluation of Death Anxiety Felt in Consumers During the Pandemic Process According to Demographic Factors}

Cansu Tor-Kadığlu a,*, Mehmet İnce ${ }^{\text {b }}$

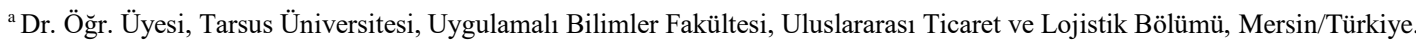
ORCID: : 0000-0003-1663-9282

${ }^{\text {b }}$ Prof. Dr. Tarsus Üniversitesi, Uygulamalı Bilimler Fakültesi, Uluslararası Ticaret ve Lojistik Bölümü, Mersin/Türkiye. ORCID: 0000-0002-0574-0361

\section{MAKALE BİLGİSI}

\section{Makale Geçmişi:}

Başvuru tarihi: 30 Eylül 2020

Düzeltme tarihi: 22 Ocak 2021

Kabul tarihi: 01 Şubat 2021

Anahtar Kelimeler:

Tüketici,

COVID-19 Pandemisi,

Ölüm Kaygısı Ölçeği

\section{ARTICLE INFO}

\section{Article history:}

Received 30 September 2020

Received in revised form 22 January 2021

Accepted 01 February 2021

\section{Keywords:}

Consumer,

COVID-19 Pandemic,

Death Anxiety Scale

\section{ÖZ}

Tüm dünyada yaşanan COVID-19 pandemisi nedeniyle toplumlar, maddi ve manevi anlamda kaygılıdır. Tüketicilerin pandemi sürecinde algıladığı manevi risklerin, tutum ve davranışlarını değiştirebileceği düşünülmektedir. Bu araştırmanın amacı, Tomas-Sabao, Gomez-Benito ve Limonero tarafindan geliştirilmiş olan "Ölüm Kaygısı Ölçeği'ni pandemi sürecine uyarlayarak tüketici grupları bakımından değerlendirmektir. Araştırmanın örneklemini, Türkiye'de yaşayan, COVID-19 pandemi sürecinde mecbur kalmadıkça evden çıkmadığını belirten, yani karantinada kalan 386 tüketici oluşturmaktadır. Çalışmanın verileri Mart-Nisan 2020 tarihinde çevrimiçi anket aracılığıyla toplanmıştır. Sonuçlar incelendiğinde; dışsal ölüm kaygısı, ölümün kabulü, ölüme ilişkin düşünceler ve ölümün kaçınılmazlığı boyutlarında; cinsiyet, yaş, gelir ve eğitim durumu bakımından anlamlı farklılıklar olduğu tespit edilmiştir.

\section{A B S T R AC T}

Due to the COVID-19 pandemic experienced all over the world, societies are financially and morally anxious. It is thought that the moral risks perceived by consumers during the pandemic process can change their attitudes and behavior. The purpose of this research is to adapt the "Death Anxiety Scale" developed by Tomas-Sabao, Gomez-Benito and Limonero to the pandemic process and evaluate it in terms of consumer groups. The sample of the study is composed of 386 consumers who live in Turkey and indicate that they do not leave the house unless they are obliged to go through the COVID-19 pandemic process, so who are in quarantine. The data of the study were collected through an online survey in March-April 2020. When the results were examined, significant differences were determined in terms of gender, age, income and education level in the dimensions of external death anxiety, acceptance of death, thoughts about death and inevitability of death.

\section{Giriş}

Ölüm kaygısı, her insanın içinde taşıdığı ve hayatın parçası olan bir faktördür. Ancak belirgin olarak kendini gösterdiğinde hatırlanmaktadır. COVID-19 salgını kendisinden önceki modern zamanların en y1kıcı olayı olmuştur. Dolayısıyla, küresel boyutta bir kaygıdan söz etmek mümkündür. Ortaya çıkan ekonomik belirsizlik, tüketicilerde ekonomiye dair bir güvensizlik ve kaygıya sebep olmakta ve tüketim niyetleri üzerinde olumsuz bir etkiye yol açmaktadır (Rio-Chanona vd., 2020:68). Pandemi sona erecek bile olsa uzun vadede ekonomik, sosyal, politik ve kültürel etkilerinin süreceği düşünülmektedir (He ve Harris, 2020:176). Epidemik hastalıkların görülmesi, insanlarda en temel korkuları meydana çıkarmaktadır. Bunlar sağlığını kaybetmek ya da hayatını kaybetmektir. Bu

\footnotetext{
* Sorumlu yazar/Corresponding author

e-posta: cansu@tarsus.edu.tr
} 
riskler hissedildiğinde tüketiciler alışkanlıklarını, tutumlarını ve davranışlarını değiştirebilmektedir (Baruönü, 2020:165). Fikirler, inançlar, değerler, alışkanlıklar ve davranışlar hem iyi hem de kötü deneyimlerden dolayı gelişmektedir; bu anlamda COVID-19 salgınının tüm bunlar üzerinde derin bir etki yaratacağı beklenmektedir (He ve Harris, 2020:179). Toplumda görülen bir epidemik ya da pandemik hastalık durumunda bireylerin duyduğu korku hissiyatı davranışlarına yön vermektedir (Baruönü, 2020: 166). Bu korkunun yoğunluğunu ve hangi tüketicilerde daha fazla görüldügünü tespit edebilmek ise önemlidir.

Küresel değişimin bir sonucu olarak, büyük salgın ve pandemilerin ortaya çıkma oranı artmaktadır. Genel olarak, 20. yüzyılın üç salgın yaşadığı kabul edilmektedir. Bunlar 1918-1919 yıllarında yaşanan İspanyol gribi, 1957'de yaşanan Asya gribi (H2N2) ve 1968'de yaşanan Hong Kong gribidir (Temel ve Ertin, 2020:64). 21. yüzyılda ise şimdiden dört salgın yaşanmıştır. 2002'de SARS, 2009'da kuş gribi, 2012'de MERS ve 2000'den beri pandemik salgınlarda görülen artışla 2013-14'te zirveye çıkan Ebola gribidir. Bu salgınların küresel değişim faktörleri ile güçlü bir şekilde ilişkili olduğu düşünülmektedir (Coker vd., 2011; Greger, 2007; Wu vd. 2017).

Uyarlanan bu ölçek ile 2020 yılında COVID-19 pandemisi ile ölüm kaygısı hisseden tüketicilerin davranışları daha anlaşılır hale gelmektedir. Çalışmada tüketicilerin ölüm kaygısı anlatılmış, tüketici ve ölüm kaygısı konulu alan yazına yer verilmiştir. Daha sonra araştırmanın yöntemi detaylı olarak anlatılmış, örneklem ve verilerin toplanması hakkında bilgi verilmiştir. Çalışmanın bulgular kısmında ise örnekleme dair demografik bulgular ve ölçeğin yap1 geçerliliğine ait istatistiki bilgiler yer almaktadır. Yine bulgular bölümünde, yapı geçerliliği ve güvenirliği sağlanarak kullanılan ölçek ve ölçeğin boyutları demografik farklılıklara göre değerlendirilmiştir. Araştırmanın sonunda ise elde edilen sonuçlar yorumlanmış ve birtakım öneriler geliştirilmiştir.

\section{Tüketicilerde Ölüm Kaygısı ve Alan Yazın Taraması}

Alderfer'in ERG modeli incelendiğinde; tüketicilerin üç ihtiyaç basamağı olduğu görülmektedir ki bunlar; varoluşsal, ilişkisel ve gelişimsel ihtiyaçlardır. Bireylerin bu basamakları tatmin etmesi gerekmektedir (Alderfer, 1969). Ancak pandemi sürecinde ve karantina durumunda her üç basamağın da tehdit altında olduğu söylemek mümkündür. Varoluş ihtiyacı, pandeminin bulaşma riski ve ölümcül olma riskini barındırması sebebiyle tehdit altındadır. İlişskisel ihtiyaçlar sosyal mesafe ve zorunlu karantina durumunda tehdit altındadır. Gelişimsel ihtiyaçlarsa, pandeminin hayat rutinlerini sekteye uğratması sebebiyle tehdit altındadır. Salgın riski tamamen ortadan kalksa dahi, kalıcı olarak değişecek tüketici davranışlarından söz etmek mümkündür (İnce ve Tor-Kadığlu, 2020: 147).

Tüketicilerdeki ölüm kaygısı üzerine yapılan çalışmalar incelendiğinde, Urien ve Kilbourne'un (2008) çalışmalarında, tüketicilerdeki ölüm kaygısı ve hayat kalitesi ilişkisine materyalizmin etkisini araştırdığı görülmektedir. Çalışmanın sonucunda, ölüm kaygısının materyalistik değerler üzerinde anlamlı bir etkisinin olduğu ortaya konmuştur. Aynı yıl Mandel ve Smeesters (2008) tarafindan yapılan bir çalışmada, tüketicilere ölümün hatırlatılmasının özellikle gıda ürünlerini satın almalarını arttırdığı saptanmıştır. Çınar (2014) tarafından yapılan bir çalışmada ölüm kaygısının ve gösterişçi tüketimin arasında ilişki saptanmaya çalışıldığ fakat bir ilişki saptanamadığı görülmüştür. Erciş vd. (2016) tarafından, ölüm kaygısının tüketici tutumları üzerindeki etkileri araştırılmıştır. Araştırmada tüketicilerin ölüm kaygısını azaltmak için sağlıklı ve doğal tüketmeye çalıştıkları ortaya konmuştur. Ölüm kaygısının ürün etiket bilgisine yönelik, ürünlerin menşeine yönelik, kâr amacı gütmeyen kurumlara yönelik ve gösterişçi tüketime yönelik anlamlı etkisi tespit edilmiştir. Larson ve Shin çalışmalarında (2018), tüketicilerin ölüm korkusu arttıç̧a faydacı ve hazcı tüketime daha fazla yöneldiklerini tespit etmiştir. Yurtsever (2019) çalışmasında, tüketicilerin ölüm kaygıları ile sigorta tercihleri üzerine bir çalışma yürütmüştür. Ölüm kaygısının sigorta tercihi üzerinde bir etkisi olmadığı anlaşılırken; kadınların erkeklere göre daha kaygılı olduğunu ve yaş arttıkça kaygının azaldığını tespit etmiştir. Knotek vd. (2020), Mart ve Nisan 2020 ayları arasında, COVID-19Amerika Birleşik Devletleri'ne yayılırken, virüsün ekonomi üzerindeki etkileri hakkında tüketicilerin inançlarında belirgin bir değişiklik olduğunu ifade etmiştir. Ayrıca, yapılan araştırmada tüketicilerin planladıkları büyük satın alımları ertelediği, işlerini kaybetmekten korktuklarına dair ifadeler tespit etmişlerdir. Balta (2020) tez çalışmasında, genç tüketicilerin bilişsel esneklik düzeyleri, ölüm kaygısı düzeyleri ve mutluluk düzeyleri arasındaki ilişkiyi incelemiştir. Bilişsel esneklik düzeyi ve ölüm kaygısı arasında pozitif yönlü anlamlı bir ilişki olduğunu saptamıştır. Ayrıca, kadınların ölüm kaygısı düzeyinin erkeklere göre ve yaşça gençlerin ise daha yaşlı olanlara göre daha fazla olduğunu ortaya koymuştur. Dündar (2020) tez çalışmasında, ölüm kaygısının tüketicileri sosyolojik ve psikolojik açıdan etkilediğini ortaya koymuştur. Çalışmanın sonuçlarına göre; ölüm kaygısı, tüketicilerde daha çok tüketmek, daha çok stoklamak ve kendilerini hayatta tutacağına inanılan ürünleri tüketmek gibi davranışlara yol açmıştır.

\section{Yöntem ve Uygulama}

Ülkemizde Mart ayında koronavirüs sebepli ölümlü vakaların görülmesiyle insanları panik, korku, endişe, kaygı sarmıştır. Bu araştırmanın amacı; "Ölüm Kaygısı Ölçeği’nin Türkçe çevirisinin pandemi sürecine uyarlayarak tüketici gruplarındaki demografik farklılıklar bakımından değerlendirmektir. $\mathrm{Bu}$ amaca yönelik, güvenirliği ve geçerliği yüksek bir ölçme aracı kullanılmıştır. Bu kapsamda, ölçme aracı önce Türkçe'ye çevrilmiştir daha sonra ölçek ifadeleri tekrar İngilizce'ye çevrilerek anlaşılırlığı kontrol edilmiştir. Daha sonra korona virüs sürecine göre uyarlanmıştır. Ülkemizde COVID-19 vakalarının görülmeye başlandığı Mart 2020 tarihi itibariyle veriler toplanmaya başlamıştır. Araştırma örneklemini, Türkiye'de yaşayan, COVID-19 pandemi sürecinde mecbur kalmadıkça evden çıkmadığını belirten, yani karantinada kalan 386 tüketici oluşturmaktadır. Yapılan bu araştırma ile 4 faktör ve 17 maddeden oluşan ölçme arac1, pandemi sürecine uyarlanarak, araştırmacıların kullanımına hazır hale getirilmiştir. Tüketicilerin olağan üstü durumlarda kaygılarını belirlemek amacıyla Şekil 1'de görülen araştırma modeline dayalı hipotezler geliştirilmiştir. 


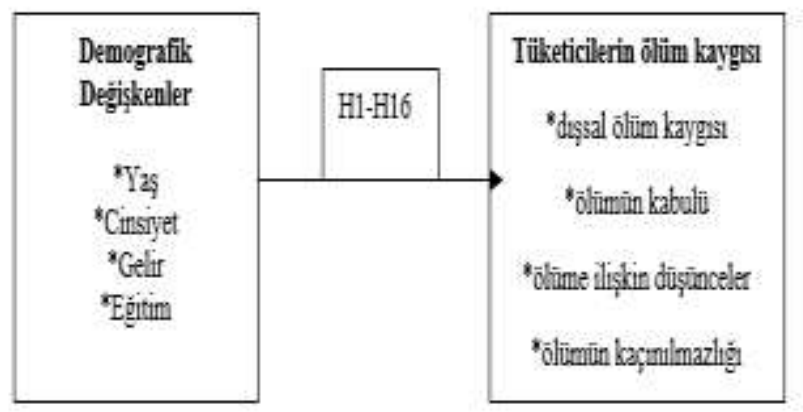

Şekil 1. Araştırma Modeli

$\mathrm{H}_{1-4}$ : Tüketicilerin hissettiği ölüm kaygısı cinsiyete göre farklılık göstermektedir.

$\mathrm{H}_{5-8}$ : Tüketicilerin hissettiği ölüm kaygısı yaşa göre farklılık göstermektedir.

$\mathrm{H}_{9-12}$ : Tüketicilerin hissettiği ölüm kaygısı gelire göre farklılık göstermektedir.

$\mathrm{H}_{13-16:}$ Tüketicilerin hissettiği ölüm kayg1sı eğitim seviyesine göre farklılık göstermektedir.

Bu çalışma, Tarsus Üniversitesi Bilimsel Araştırma ve Yayın Etiği Kurulu'nca araştırma etiği yönünden değerlendirilmiştir. Kurulun, 05.03.2020 tarihli ve 2020/171 sayılı kararı ile etik yönden uygun bulunmuştur.

\section{1. Örneklem ve Verilerinin Toplanması}

Araştırmanın örneklemini pandemi sürecinde karantina durumunu yaşamış tüketiciler oluşturmaktadır. Bazı araştırmalarda kullanılan ölçekteki ifade sayısının 5 katı kadar örnekleme ulaşılması yeterli görülürken (Nunnally, 1978: 180; Comrey ve Lee, 1992: 216-217), baz1 çalışmalarda 10-15 katı örnekleme ulaşılması uygun bulunmaktadır (Nunnally ve Bernstein, 1994: 542 ; Pett vd., 2003: 62). Bu araştırmada, önerme sayısının en az 15 katı kadar katılımcıya ulaşılması amaçlanmıştır. Kullanılan ölçekte 17 ifade bulunmaktadır. Bu durumda 255 katılımcıya ulaşılması yeterlidir. Çalışma 386 kişi ile yürütülmüştür, bu anlamda çalışılan örneklem sayısının yeterli olduğu söylenebilir. Araştırmada Tomas-Sabao vd. (2005) tarafından geliştirilen Ölüm Kaygısı Ölçeği pandemi sürecine uyarlanarak kullanılmıştır. Tomas-Sabado ve Gomez-Benito tarafindan 2005 yilında, 20 madde ile geliştirilen Ölüm Kaygısı Ölçeği beş faktörlü yapıdadır. Aynı yıl Tomas-Sabao, Gomez-Benito ve Limonero tarafından yapılan çalışmada sorunlu olan 3 madde ölçekten çıkarılarak ölçek revize edilmiştir. Elde edilen ölçek 17 maddelik 4 boyutlu bir yapıdadır. Yapılan faktör analizi çalışmasında ölçeğin, "ölümün kabulü”, “dışsal ölüm kaygısı", “ölümün kaçınılmazlığg” ve "ölüme ilişkin düşünceler" adlı dört boyutu içerdiği belirlenmiştir. Çalışmanın verileri Mart-Nisan 2020 tarihinde, tüketiciler karantina dönemini yaşarken çevrimiçi anket aracılığıyla toplanmıştır.

\section{Bulgular}

$\mathrm{Bu}$ bölümde katılımcıların cinsiyetleri, yaşları, eğitim durumları ve hane halkı gelirleri ile alakalı elde edilen istatistiki bilgiler Tablo 1'de sunulmuştur. Bu bilgiler sayı ve yüzde olarak ifade edilmiş ve yorumlanmıştır.
Tablo 1. Demografik Bulgular

\begin{tabular}{|c|c|c|c|c|c|}
\hline Cinsiyeti & $\mathbf{n}$ & $\%$ & Yaşı & $\mathbf{n}$ & $\%$ \\
\hline \multirow{3}{*}{$\begin{array}{l}\text { Erkek } \\
\text { Kadın }\end{array}$} & \multirow{3}{*}{$\begin{array}{l}213 \\
173\end{array}$} & \multirow{3}{*}{$\begin{array}{l}55,2 \\
44,8\end{array}$} & $18-31$ & 141 & 36,5 \\
\hline & & & $32-39$ & 147 & 38,1 \\
\hline & & & $40 \leq$ & 98 & 25,5 \\
\hline Mezuniyet & $\mathbf{n}$ & $\%$ & $\begin{array}{ll}\text { Aile Geliri } \\
\text { TL }\end{array}$ & $\mathbf{n}$ & $\%$ \\
\hline Lise ve alt1 & 71 & 18,4 & $\leq 4000$ & 103 & 26,7 \\
\hline Ön/Lisans & 249 & 64,5 & $4001-8000$ & 167 & 43,3 \\
\hline Lisansüstü & 66 & 17,1 & $\geq 8001$ & 116 & 30,1 \\
\hline Toplam & 386 & 100 & Toplam & 386 & 100 \\
\hline
\end{tabular}

Demografik bulguları gösteren Tablo 1 incelendiğinde, ankete katılım gösteren 386 tüketicinin \%55,2'sinin kadın, $\% 44,8$ 'inin ise erkek olduğu görülmektedir. Katılımcıların \%38'i 32-39 yaş aralığında bireylerden oluşmaktadır. Eğitim durumlarına bakıldığında, 386 katılımcının büyük çoğunluğunun $(\% 64,5)$, ön lisans veya lisans mezunu olduğu görülmektedir. Hane halkı gelir durumu incelendiğinde ise \%43,3' ünün gelir durumunun 4001-8000 TL arasında olduğu anlaşılmaktadır.

\section{1. Ölçeğin Güvenirlik Analizi}

Pandemi sürecine uygun hale getirilerek kullanılan ölçeğe ait boyutların, boyutlara ait ifadelerin, ifadelere ait ortalama değerler ve standart sapma değerlerinin görüldüğü Tablo 2 içerisinde; boyutların ve genel ölçek yapısının güvenirliği de yer almaktadır. Güvenilirlik değerini ifade eden Cronbach's Alpha değerinin 0,70 ve üzerinde olduğu durumlarda, o ölçeğin dolayısıyla da kullanılan ölçeğin güvenilir olduğu ifade edilmektedir (Durmuş vd., 2013, s.89)

Tablo 2. İfadelere Ait Ortalama ve Güvenirlik Değeri Tablosu

\begin{tabular}{|c|c|c|c|c|}
\hline & Iffade & Ortalama & St. Sapma & $\boldsymbol{\alpha}$ \\
\hline \multirow{4}{*}{ 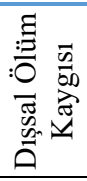 } & DOK1 & 4,80 & 0,72 & \multirow{4}{*}{684} \\
\hline & DOK2 & 3,73 & 1,42 & \\
\hline & DOK3 & 4,24 & 1,10 & \\
\hline & DOK4 & 4,11 & 1,26 & \\
\hline \multirow{6}{*}{ 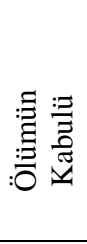 } & OK1 & 3,40 & 1,53 & \multirow{6}{*}{, 704} \\
\hline & $\mathrm{OK} 2$ & 4,08 & 1,25 & \\
\hline & OK3 & 1,96 & 1,34 & \\
\hline & OK4 & 3,14 & 1,41 & \\
\hline & OK5 & 2,59 & 1,57 & \\
\hline & OK6 & 3,26 & 1,42 & \\
\hline \multirow{3}{*}{ 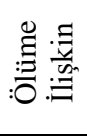 } & OID1 & 3,80 & 1,28 & \multirow{3}{*}{, 775} \\
\hline & OID2 & 3,59 & 1,44 & \\
\hline & OID3 & 2,76 & 1,42 & \\
\hline \multirow{4}{*}{ 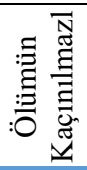 } & KAC1 & 2,41 & 1,51 & \multirow{4}{*}{,722 } \\
\hline & KAC2 & 3,89 & 1,41 & \\
\hline & KAC3 & 4,25 & 1,25 & \\
\hline & KAC4 & 4,35 & 1,04 & \\
\hline
\end{tabular}

Tablo 2'de yer alan boyutlar incelendiğinde, dişsal ölüm kaygısı boyutuna ait 4 ifadenin güvenirlik değeri 0,684 iken; ölümün kabulü boyutu 0,704; ölüme ilişkin düşünceler boyutu 0,775 ve ölümün kaçınılmazlığı boyutu 0,722 güvenirlik derecesindedir. Kullanılan ölüm kaygısı ölçeğinin genel olarak güvenirlik değerinin 0,896 olduğu hesaplanmıştır. $\mathrm{Bu}$ durumda ölçeğin güvenilir olduğu söylenebilmektedir. İfadelere ait ortalama değerler 
incelendiğinde, $\mathrm{OK} 3$ ve $\mathrm{KAC} 1$ ifadelerinin ortalamalarının diğer ifadelere nazaran daha düşük olduğu göze çarpmaktadır.

AMOS programı aracılı̆̆ı ile ölçeğe doğrulayıcı faktör analizi uygulanmıştır. Birinci düzey çok faktörlü yapıya sahip olan ölçeğe ait boyutlar, ifadeler ve ölçek dışı bırakılan ifadeler Tablo 3 'te yer almaktadır.

Tablo 3. Ölçek İfadelerinde Revizyon

\begin{tabular}{lllll}
$\begin{array}{lllll}\text { Ölçek } \\
\text { İsmi }\end{array}$ & Boyutlar & İfadeler & $\begin{array}{l}\text { Çıarılan } \\
\text { İfadeler }\end{array}$ & \\
\hline & DOK & 4 & 1 & Birinci \\
Ölüm & OK & 6 & - & Düzey \\
Kaygıs1 & OID & 3 & - & Çok \\
Ölçeği & KAC & 4 & 1 & Faktörlü \\
& & & & \\
\hline
\end{tabular}

Tablo 3'ten anlaşılacağı üzere DOK3 ile KAC1 kodlu iki ifade ölçek dışı bırakılmıştır. Bu şekilde 17 ifadeden oluşan ölçek, 15 ifadeli haliyle kullanılmaktadır. Ayrıca 'ölümün kabulü' boyutuna ait OK3 ve OK5 kodlu ifadeler ile 'ölüme ilişkin düşünceler' boyutuna ait OID2 ve OID3 kodlu ifadeler arasında kovaryans bağlantısı yapılmıştır. Yapılan kovaryans bağlantıları ölçeğin yapısını bozmayacak şekilde ve programın önerisi doğrultusunda gerçekleştirilmiştir. Birinci düzey çok faktörlü yapıya sahip ölüm kaygısı ölçeğinin boyutları üzerine yapılan doğrulayıcı faktör analizi Şekil 2'de yer almaktadır.

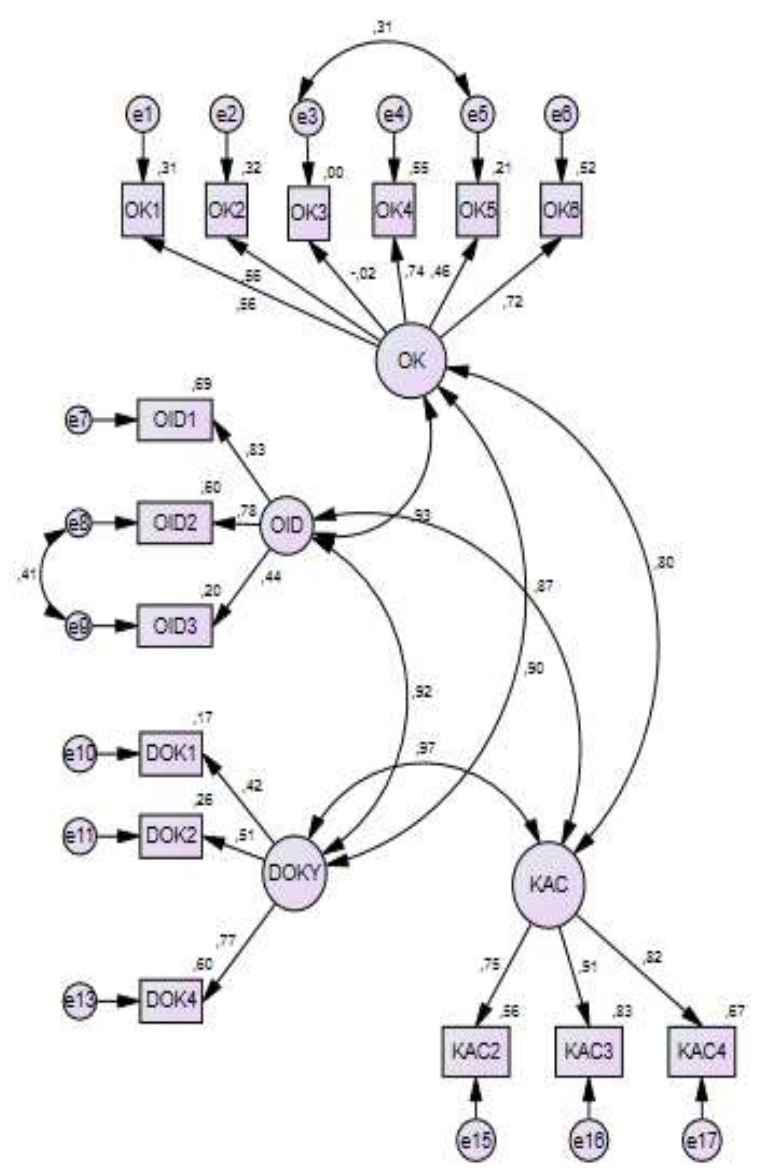

Şekil 2. Ölçeğe Ait Doğrulayıcı Faktör Yapısı

Doğrulayıcı faktör yapısının geçerli ve güvenilir bir yapıda olduğunu doğrulayabilmek için, AMOS programı ile elde edilen uyum iyiliği değerlerinin belli aralıklarda olması beklenmektedir. $\mathrm{Bu}$ değerlere ilişkin kabul gören aralıklar; iyi uyum değerleri ve kabul edilebilir uyum değerleri olarak iki şekilde ele alınmaktadır. İstenen uyum değerlerine ait bilgiler Tablo 4 'te yer almaktadır.

Tablo 4. İstenen Uyum İyiliği Değerleri

\begin{tabular}{|c|c|c|c|c|c|}
\hline & $X^{2}$ df & $\mathrm{X}$ idf & GH & CFI & RUSEA \\
\hline lyi Uyum Degerlen' & & $\leq 3$ & $\geq 0,90$ & $\geq 0,97$ & $\leq 0,05$ \\
\hline $\begin{array}{c}\text { Kabul Edilebilir Uyum } \\
\text { Degierlen" }\end{array}$ & & $\leq 4.5$ & $0,89-0,85$ & $\geq 0,95$ & $0,05-0,08$ \\
\hline
\end{tabular}

(Kaynak: Meydan ve Şeşen, 2011: 37)

Tablo 5'te araştırmada kullanılan ölüm kaygısı ölçeğinin, doğrulayıcı yapısına ait elde edilen uyum iyiliği değerleri yer almaktadır.

Tablo 5. Kullanılan Ölçeğin Uyum İyiliği Değer Tablosu

\begin{tabular}{llllll}
$\mathbf{X}^{\mathbf{2}}$ & df & $\mathbf{X}^{\mathbf{2}} / \mathbf{d f}$ & GFI & CFI & RMSEA \\
\hline 382,68 & 82 & 4,667 & 0,883 & 0,890 & 0,078 \\
\hline
\end{tabular}

Ölçeğe ait değerler incelendiğinde, tüm değerlerinin kabul edilebilir uyum iyiliği değerleri arasında olduğunu söylemek mümkündür. Ayrıca, ölçek dışı bırakılan iki ifade sonrası tekrar hesaplanan güvenilirlik değerlerine, ifadelere ait faktör yüklerine, faktör yükleri vasıtasıyla hesaplanan AVE ve CR değerlerine Tablo 6'da yer verilmiştir.

Tablo 6. İfadelere Ait İstatistiki Bulgular

\begin{tabular}{|c|c|c|c|c|c|}
\hline Değişken & Kod & $\begin{array}{l}\text { Faktör } \\
\text { Yükü } \\
\end{array}$ & AVE & CR & $\begin{array}{l}\text { Cro. } \\
\text { Alfa }\end{array}$ \\
\hline \multirow{3}{*}{ 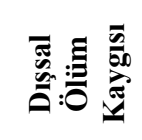 } & DOK1 & 0,415 & \multirow{3}{*}{0,345} & \multirow{3}{*}{0,601} & \multirow{3}{*}{0,689} \\
\hline & DOK2 & 0,513 & & & \\
\hline & DOK4 & 0,775 & & & \\
\hline \multirow{6}{*}{ 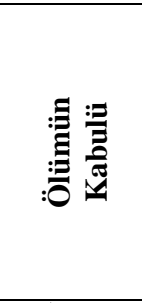 } & OK1 & 0,558 & \multirow{6}{*}{0,319} & \multirow{6}{*}{0,697} & \multirow{6}{*}{$\mathbf{0 , 7 0}$} \\
\hline & OK2 & 0,564 & & & \\
\hline & OK3 & 0,015 & & & \\
\hline & OK4 & 0,743 & & & \\
\hline & OK5 & 0,462 & & & \\
\hline & OK6 & 0,722 & & & \\
\hline \multirow{3}{*}{ 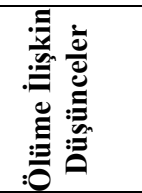 } & OID1 & 0,830 & \multirow{3}{*}{0,495} & \multirow{3}{*}{0,734} & \multirow{3}{*}{0,775} \\
\hline & OID2 & 0,775 & & & \\
\hline & OID3 & 0,442 & & & \\
\hline \multirow{3}{*}{ : } & KAC2 & 0,746 & \multirow{3}{*}{0,688} & \multirow{3}{*}{0,868} & \multirow{3}{*}{$\mathbf{0 , 8 5 0}$} \\
\hline & KAC3 & 0,913 & & & \\
\hline & KAC4 & 0,821 & & & \\
\hline
\end{tabular}

Tablo 6 incelendiğinde, faktör yüklerinin büyük çoğunluğunun 0,70 'in üzerinde olduğu görülmektedir. Güvenilirlik değerini ifade eden Cronbach's Alpha değerinin 0,70 ve üzerinde olduğu durumlarda, o ölçeğin dolayısıyla da çalışmanın, güvenilir olduğu anlaşılmaktadır (Durmuş vd., 2013:89). Fornell ve Larcker (1981) hesaplanan AVE 
değerlerinin 0,50'den büyük olması, gerektiğini, ayrıca CR değerlerinin de AVE değerlerinden fazla olması gerektiğini belirtmiştir. AVE değerinin 0,50'nin altında kalması durumunda, CR değeri kontrol edilmelidir, CR'nin 0,60'tan büyük olması halinde yapı geçerliliğinin sağlandığı kabul edilmektedir (Huang vd., 2013, 219). Bu araştırmaya ait AVE ve CR değerleri incelendiğinde çalışmanın yapı geçerliliğinin sağlandığı rahatlıkla söylenebilmektedir. Ayrıca, Tablo 2 ve Tablo 6'da bulunan güvenirlik değerleri karşılaştırıldığında, silinen iki ifadeye ait boyutların güvenirlik değerlerinin yükseldiği görülmektedir. $\mathrm{Bu}$ da programın önerisi doğrultusunda silinen ifadelerin genel yapıyı bozduğunu doğrular niteliktedir.

\subsection{Bulguların Demografik Değişkenlere Göre Değerlendirilmesi}

Bu araştırmada tüketicilerin hissettiği ölüm kaygısı 4 boyutta ele alınmıştır. Katılımcıların cinsiyetlerine, yaşlarına, gelirine ve eğitim derecesine göre algılanan ölüm kaygısının farklılık göstereceği ön görülmüştür. $\mathrm{Bu}$ minvalde kurulan hipotezlere dair yapılan analizlerin sonuçlarına Tablo 7'de yer verilmiştir. Tablo 7 içerisinde ilgili değişkenler, araştırılan boyutlar, her boyut için hesaplanan $\mathrm{p}$ değerleri ve hipotezlerin kabul durumları yer almaktadır. Cinsiyet, yaş, gelir ve eğitim durumu değişkenleri ve ölçekte bulunan dört boyut arasında 16 farklı hipotez kurulmuştur. $\mathrm{Bu}$ hipotezler test edilirken, t-test, ANOVA ve MANOVA testlerinden faydalanılarak $\mathrm{p}$ değerleri hesaplanmıştır. Anlamlılık düzeyini gösteren $\mathrm{p}$ değerinin 0.05 'in altında olduğu durumlarda hipotezler kabul edilirken, anlamlılık düzeyi 0,05'in üzerinde olduğu durumlarda hipotezler reddedilmiştir.

Tablo 7. Hipotez Sonuçlarına Ait Özet Tablo

\begin{tabular}{|c|c|c|c|}
\hline $\begin{array}{l}\text { İlgili } \\
\text { Değişken }\end{array}$ & Boyut & $\begin{array}{l}\mathrm{P} \\
\text { değeri }\end{array}$ & $\begin{array}{l}\text { Kabul } \\
\text { Durumu }\end{array}$ \\
\hline \multicolumn{4}{|c|}{$\begin{array}{l}\text { HI-4: Tüketicilerin hissettiği ölüm kaygısı cinsiyetlerine göre } \\
\text { farklılık gösterir. }\end{array}$} \\
\hline \multirow{5}{*}{ Cinsiyet } & Dıșsal Ölüm Kaygısı & 0,000 & Kabul \\
\hline & Ölümün Kabulü & 0,036 & Kabul \\
\hline & Ölümün Kaçınılmazlı̆̆ 1 & 0,000 & Kabul \\
\hline & Ölüme İlişkin & 0,001 & Kabul \\
\hline & Düşünceler & & \\
\hline \multicolumn{4}{|c|}{$\begin{array}{l}\text { H5-8: Tüketicilerin hissettiği ölüm kaygısı yaşlarına göre } \\
\text { farklılık gösterir. }\end{array}$} \\
\hline \multirow{5}{*}{ Yaş } & Dışsal Ölüm Kaygısı & 0,000 & Kabul \\
\hline & Ölümün Kabulü & 0,018 & Kabul \\
\hline & Ölümün Kaçınılmazlığ & 0,000 & Kabul \\
\hline & Ölüme İlişkin & 0,000 & Kabul \\
\hline & Düşünceler & & \\
\hline \multicolumn{4}{|c|}{$\begin{array}{l}\text { H9-12: Tüketicilerin hissettiği ölüm kaygısı gelirlerine göre } \\
\text { farklılık gösterir. }\end{array}$} \\
\hline \multirow{5}{*}{ Gelir } & D1şsal Ölüm Kaygısı & 0,000 & Kabul \\
\hline & Ölümün Kabulü & 0,004 & Kabul \\
\hline & Ölümün Kaçınılmazlığ & 0,002 & Kabul \\
\hline & Ölüme İlişkin & 0,000 & Kabul \\
\hline & Düşünceler & & \\
\hline \multicolumn{4}{|c|}{$\begin{array}{l}\text { H13-16: Tüketicilerin hissettiği ölüm kaygısı eğitimlerine göre } \\
\text { farklılık gösterir }\end{array}$} \\
\hline \multirow{5}{*}{$\begin{array}{l}\text { Eğitim } \\
\text { Durumu }\end{array}$} & D1şsal Ölüm Kaygısı & 0,002 & Kabul \\
\hline & Ölümün Kabulü & 0,024 & Kabul \\
\hline & Ölümün Kaçınılmazlığı & 0,065 & Ret \\
\hline & Ölüme İlişkin & 0,003 & Kabul \\
\hline & Düşünceler & & \\
\hline
\end{tabular}

Tablo 7 incelendiğinde araştırmaya başlarken kurulan 16 hipotezin 15 'inin kabul edilirken 1 tanesinin reddedildiği görülmüştür. Tüketicilerin hissettiği ölümün kaçınılmazlığ boyutunun eğitim derecesine göre bir farklılık yaratmadığ anlaşılmıştır. Farklılık olduğu ispatlanan diğer hipotezler için bağımsız t-testi, tek yönlü ANOVA testi ve MANOVA testleri uygulanmıştır. Farklılıkların hangi gruplardan kaynaklandığını anlamak için Post Hoc sekmesinden LSD ve Bonferroni testleri seçilmiştir.

Gruplar arası farklara bakıldığında ise kadın tüketicilerin erkeklere kıyasla, tüm boyutlarda daha fazla kaygı taşıdığı; yaşı 18-31 arasında olan tüketicilerin yaşça daha büyük tüketicilere kıyasla daha kaygılı olduğu; geliri düşük olan tüketicilerin geliri yüksek olanlara kıyasla daha kaygılı olduğu görülmüştür. Eğitim seviyesi düşük olan tüketicilerin, eğitim seviyesi yüksek olanlara kıyasla; dışsal ölüm kaygısı, ölümün kabulü ve ölüme ilişkin düşünceler boyutlarında daha kaygılı olduğu anlaşılmıştır. Ölümün kaçınılmazlığı boyutunda ise eğitim seviyesinin bir farklılık yaratmadığı saptanmıştır. Cinsiyet değişkeninde görülen farklılığın her boyut için detaylı gösterimi Tablo 8'de yer almaktadir.

Tablo 8. Tüketicilerin Hissettiği Ölüm Kaygısının Cinsiyete Göre Farklılı̆̆ını Gösteren Tablo

\begin{tabular}{lllll}
\hline & $\begin{array}{l}\text { Cinsiyet } \\
\text { etmeni }\end{array}$ & Ortalama & $\begin{array}{l}\text { Standart } \\
\text { Sapma }\end{array}$ & Sig \\
\hline DOK & Kadın & 4,38 & 0,697 & 0,000 \\
& Erkek & 4,03 & 0,958 & \\
\hline OK & Kadın & 3,16 & 0,880 & 0,036 \\
& Erkek & 2,97 & 0,933 & \\
\hline KAC & Kadın & 3,91 & 0,850 & 0,000 \\
& Erkek & 3,51 & 1,067 & \\
\hline OID & Kadın & 3,56 & 1,103 & 0,001 \\
& Erkek & 3,16 & 1,178 & \\
\hline
\end{tabular}

Tablo 8 incelendiğinde, tüketicilerin hissettiği ölüm kaygısının tüm boyutlarıyla cinsiyet değişkeni açısından farklılık göstermekte olduğu anlaşılmaktadır. Bu durumda kurulan $\mathrm{H}_{1}, \mathrm{H}_{2}, \mathrm{H}_{3}$ ve $\mathrm{H}_{4}$ hipotezleri, anlamlılık düzeyi $\mathrm{p}<0,05$ 'den küçük olduğundan kabul edilmiştir. Kullanılan ölçeğin dört boyutunda da kadın tüketicilerin ölüm kaygısı düzeyinin erkek tüketicilerden daha fazla olduğu tespit edilmiştir. Ulaşılan bu sonuç alan yazındaki diğer çalışmalarla (Yurtsever, 2019; Balta, 2020) paralellik göstermektedir. Tablo 9'da, hissedilen ölüm kaygısının yaşlara göre farklılığına dair analiz sonuçlarına yer verilmiştir. 
Tablo 9. Tüketicilerin Hissettiği Ölüm Kaygısının Yaşlarına Göre Farklılı̆̆ını Gösteren Tablo

\begin{tabular}{|c|c|c|c|c|}
\hline & \multicolumn{2}{|c|}{$\begin{array}{l}\text { Arasında fark olan yaş } \\
\text { grupları }\end{array}$} & \multirow{2}{*}{$\begin{array}{l}\text { Ortalamalar } \\
\text { Fark1 }\end{array}$} & \multirow{2}{*}{$\begin{array}{l}p \text { değeri } \\
0,000\end{array}$} \\
\hline \multirow{2}{*}{ DOK } & 18-31 yaş & 40 yaş ve üzeri & & \\
\hline & 32-39 yaş & 40 yaş ve üzeri & 0,3990 & 0,001 \\
\hline OK & $18-31$ yaş & 40 yaş ve üzeri & 0,3340 & 0,015 \\
\hline \multirow{2}{*}{ KAC } & 18-31 yaş & 40 yaş ve üzeri & 0,5900 & 0,000 \\
\hline & $32-39$ yaş & 40 yaş ve üzeri & 0,4080 & 0,003 \\
\hline \multirow{3}{*}{ OID } & $18-31$ yaş & 32-39 yaş & 0,3820 & 0,011 \\
\hline & $18-31$ yaş & 40 yaş ve üzeri & 0,8150 & 0,000 \\
\hline & 32-39 yaş & 40 yaş ve üzeri & 0,4330 & 0,009 \\
\hline
\end{tabular}

Tablo 9 incelendiğinde, elde edilen anlamlılık düzeylerinin 0,05 'in altında olmasi neticesinde, $\mathrm{H}_{5}, \mathrm{H}_{6}, \mathrm{H}_{7}$ ve $\mathrm{H}_{8}$ hipotezleri kabul edilmiştir. Gruplar arası farklılıkları anlamak için Post Hoc testine başvurulmuştur. Katılımcılar gelir açısından 18-31 yaş, 32-39 yaş, 40 yaş ve üzeri olmak üzere üç grupta ele alınmıştır. Verilere göre, her dört boyut için de yaşça genç olan tüketicilerin ölüm kaygısının, yaşça büyüklere kıyasla daha fazla olduğu görülmüştür. Elde edilen bu sonucun diğer araştırma sonuçlarıyla (Yurtsever, 2019; Balta, 2020) benzerlik gösterdiği tespit edilmiştir.

Tablo 10. Tüketicilerin Hissettiği Ölüm Kaygısının Gelire Göre Farklılı̆̆ını Gösteren Tablo

\begin{tabular}{lllll}
\hline & \multicolumn{2}{l}{ Arasında fark olan gelir grupları } & Ort.Fark1 & p değeri \\
\hline \multirow{2}{*}{ DOK } & 4000 TL ve altı & 8001 ve üstü TL & 0,5190 & 0,000 \\
& $4001-8000$ TL & 8001 ve üstü TL & 0,3540 & 0,001 \\
\hline OK & $4001-8000$ TL & 8001 ve üstü TL & 0,3510 & 0,004 \\
\hline \multirow{2}{*}{ KAC } & 4000 TL ve altı & 8001 ve üstü TL & 0,4220 & 0,004 \\
& $4001-8000$ TL & 8001 ve üstü TL & 0,3590 & 0,006 \\
\hline \multirow{2}{*}{ OID } & 4000 TL ve altı & 8001 ve üstü TL & 0,6350 & 0,000 \\
& $4001-8000$ TL & 8001 ve üstü TL & 0,4250 & 0,006 \\
\hline
\end{tabular}

Tüketicilerin gelirlerinin hissettikleri ölüm kaygısında bir farklılık yaratıp yaratmadığını anlamak için yapılan analizde, $\mathrm{p}<0,05$ sonucunda her dört boyutta da ulaşılmıştır. Bu durumda $\mathrm{H}_{9}, \mathrm{H}_{10}, \mathrm{H}_{11}, \mathrm{H}_{12}$ hipotezleri kabul edilmiştir. Katılımc1lar gelirlerine göre 4000 TL ve altı, 4001-8000 TL ve 8001 TL ve üstü olarak ele alınmıştır. Gruplar arası farklılık incelendiğinde, geliri düşük olan tüketicilerin geliri yüksek olan tüketicilere kıyasla daha fazla ölüm kaygısı hissettiği anlaşılmıştır. Tüketicilerin eğitim durumları ve hissettikleri ölüm kaygısı boyutlarına ilişkin analiz sonuçları Tablo 11'de yer almaktadır.
Tablo 11. Tüketicilerin Hissettiği Ölüm Kaygısının Eğitim Derecesine Göre Farklılığını Gösteren Tablo

\begin{tabular}{lllll}
\hline \multicolumn{4}{l}{ Arasında fark olan eğitim grupları } & $\begin{array}{l}\text { Ort. } \\
\text { Fark1 }\end{array}$ \\
\hline \multirow{2}{*}{ DOK } & En az lise mez. & Lisansüstü mezunu & 0,4967 & 0,001 \\
& Ön/Lisans mez. & Lisansüstü mezunu & 0,2920 & 0,011 \\
\hline OK & En az lise mez. & Lisansüstü mezunu & 0,3821 & 0,014 \\
& Ön/Lisans mez. & Lisansüstü mezunu & 0,3104 & 0,013 \\
\hline OID & En az lise mez. & Lisansüstü mezunu & 0,6620 & 0,001 \\
& Ön/Lisans mez. & Lisansüstü mezunu & 0,4123 & 0,009 \\
\hline
\end{tabular}

Araştırmaya katılanların eğitim düzeyi; en az lise mezunu, ön/lisans mezunu ve lisansüstü mezunu olarak gruplandırılmıştır. Dışsal ölüm kaygısı, ölümün kabulü ve ölüme ilişkin düşünceler boyutlarında anlamlı farklılık tespit edildiğinden; $\mathrm{H}_{13}, \mathrm{H}_{14}$ ve $\mathrm{H}_{16}$ hipotezleri kabul edilmiştir. Sadece ‘ölümün kaçınılmazlığı' boyutunda eğitim düzeyi ne olur olsun bir farklılık olmadığı saptanmıştır ve $\mathrm{H}_{15}$ hipotezi p değerinin 0,05 'ten yüksek olması sebebiyle reddedilmiştir. Farklılık tespit edilen boyutlar incelendiğinde; tüketicilerin eğitim düzeyi yükseldikçe hissettikleri dışsal ölüm kaygısı, ölümün kabulü ve ölüme ilişkin düşünceler boyutlarında, kaygı düzeyinin azaldığı tespit edilmiştir.

\section{Sonuç ve Öneriler}

İnsan, her daim tüketen ve tüketmeye devam eden bir varlıktır. Bireyleri tüketime iten birçok sebep bulunmaktadır. Ölüm kaygısı da bu sebeplerden bir tanesidir. Bu araştırmanın amacı; pandemi ve karantina gibi olağan üstü durumlarda tüketicilerin ölüm kaygılarını belirlemek ve demografik değişkenlere göre oluşan farklılıkları ortaya koymaktır. Bu kapsamda, ölçme aracı önce Türkçe'ye çevrilmiştir sonra korona virüs sürecine göre uyarlanmıştır. Ölçeğin güvenirliği test edildikten sonra, AMOS programı vasıtasıyla doğrulayıcı faktör analizi uygulanmıştır. Yapılan analiz sonucunda, kullanılan ölçeğin yapısı geçerli ve güvenilir bulunmuştur. Ölçek maddelerinin yüksek ayırt ediciliğe sahip olduğu görülmüştür. Ölçeğe ait iki ifade programın önerisi doğrultusunda ölçek dışı bırakmıştır. Elde edilen veriler, korona sebepli karantina sürecinde, Ölüm Kaygısı Ölçeği'nin Türkiye örneklemi için geçerli ve güvenilir bir ölçüm aracı olarak kullanılabileceğini ortaya koymaktadır.

Elde edilen verilere göre; dışsal ölüm kaygısı, ölümün kabulü, ölüme ilişkin düşünceler ve ölümün kaçınılmazlığ boyutlarının; yaş, cinsiyet, gelir ve eğitim durumu değişkenlerine göre farklılık gösterdiği anlaşılmıştır. Farklılık yaratan gruplar arası karşılaştırma yapıldığında ise, kadın tüketicilerdeki ölüm kaygısı düzeyinin erkeklere göre; yaşları genç tüketicilerin (18-31 yaş), yaşça büyük tüketicilere göre (32-39 yaş, 40 ve üzeri yaş) fazla olduğu tespit edilmiştir. Aile gelir düzeyi düşük olan tüketicilerin, geliri yüksek olanlara göre ölüm kaygısını daha derinden hissettiği görülmüştür. Eğitim düzeyi ile ilgili yapılan analizde, 'dışsal ölüm kaygısı, ölümün kabulü ve ölüme ilişkin düşünceler' isimli 3 boyutta; eğitim düzeyi yükseldikçe kaygı düzeyinin düştüğü anlaşılmaktadır. Sadece ölümün kaçınılmazlığı boyutunda eğitim düzeyinin bir farklılık yaratmadığı tespit edilmiştir.

Alan yazında konu ile ilgili yapılan çalışmalar incelendiğinde özellikle 2020 yılının ikinci yarısında artış gösterdiği görülmüştür. COVID-19'un çevrimiçi satın 
alımlara etkisini (Danışmaz, 2020); çevrimiçi kitap satın alımlarına etkisini (Nguyen, 2020); tüketicilerin stoklama ve online satın alımlarına etkisini (İnce ve Tor-Kadığlu, 2020); teknolojik stratejilere etkisini (Elavarasan ve Pugazhendhi, 2020); meyve ve sebze pazarına etkisini (Richards ve Rickard, 2020); sosyal, ekonomik ve halk sağlığına etkisini (Cavmak vd., 2020); kurumsal sosyal sorumluluğa etkisini (He ve Harris, 2020); tüketicilerin yaşam tarzlarına etkisini (Çakıroğlu vd., 2020); Çin'deki tüketicilerin yaşam stilleri ve seyahatlerine etkisini (Wen vd. 2020); Kanada'daki perakende gida ve yemek hizmetine olan etkisini (Goddard, 2020) araştıran birçok araştırmaya rastlanmıştır.

Yapılan bu çalışma ile benzer çıkarımlarda bulunan Stanciu vd (2020)'nin Romanya'da yürüttükleri çalışma incelendiğinde; kriz durumlarında tüketici davranışlarının değiştiği görülmüştür. Kriz halini yaşayan tüketicilerin iyiliği için, medikal sistemlere ve binalara yatırım yapılması gerektiğini, daha esnek bir eğitim sistemine geçilmesini, yüzyüze yapılan eğitimlerin ve kursların çevrimiçi şekilde sürdürülmesi gibi bir takım öneriler geliştirilmiştir.

Birimoğlu-Okuyan vd. (2020) tarafından hemşirelik öğrencilerinin sağlık kaygı düzeyi üzerine yapılan araştırmada, katılımcıların büyük çoğunluğunun psikolojik desteğe ihtiyaç duyduğu, sıkıntılı, bunalmış, gergin ve öfkeli hissettiği ortaya konmuştur. (Birimoğlu-Okuyan vd., 2020).

Ladikli vd. (2020), Ahorsu vd. (2020) tarafından geliştirilen COVID-19 korku ölçeğinin güvenirlik ve geçerliliğini test eden bir araştırma yapmışlardır. Türkçe uyarlamada gerekli koşulları sağladığı ve kullanılabilir olduğu anlaşılmıştır.

Sektörel bir öneri getirilmesi gerekirse, tüketicilerde tespit edilen ölüm kaygısı sebebiyle teknoloji yoğun hizmetlerin arttırılması tavsiye edilmektedir. Tüketicilerin, verimli şekilde uzaktan eğitim alabildiği, çevrimiçi bankacılık işlemi yapabildiği, kolaylıkla çevrimiçi mal / hizmet sipariş edebildiği ve kişisel temasın az olduğu mecraları tercih edeceği ön görülmektedir. $\mathrm{Bu}$ durumda pazarlama sektöründeki firmalara; yapay zekâ, drone kullanımı, 5G ve akıllı uygulamalar, robot sistemi kullanımına ağırlık vermesi önerilmektedir. Ayrıca, firmalara çevrimiçi satış ve tutundurma kanallarını daha verimli kullanması, hijyen standartlarının sağlandığı ambalajlı ürünlere yönelmesi de önerilmektedir.

$\mathrm{Bu}$ çalışma ile pandemi sürecinde karantinada kalan tüketiciler için uyarlanan ölüm kaygısı ölçeği, araştırmacılar için güvenilir ve hazır hale getirilmiştir. Gelecekte bu konu ile ilgili çalışma yapacaklara, tüketicilerdeki ölüm kaygısının; çevrimiçi satın alma, stoklama, daha fazla ödeme istekliliği gibi değişkenlerle muhtemel ilişkilerine yönelik araştırmalar önerilebilir. Ayrıca araştırma ülkemizde ilk ölümlü vakanın tespit edildiği ve tüketicilerin zorunlu karantinada olduğu Mart ayında yapılmıştır. Tüketicilerdeki pandemik farkındalık düzeyi ve normalleşme arttıkça, ölüm kaygısının düşeceği ön görülmektedir. $\mathrm{Bu}$ anlamda bu verilerin 'yeni normal' döneminde tekrar toplanarak, pandemi dönemi ve yeni normal dönemini karşılaştıran bir analiz yapılması da öneriler arasındadır.

\section{Kaynakça}

Alderfer C.P. (1969). An Empirical Test of a New Theory of Human Needs. Organizational Behavior and Human Performance, 4: 142-175.

Balta, Ş. N. (2020). Genç yetişkin bireylerin bilişsel esneklik düzeylerinin, ölüm kaygısl düzeyleri ve mutluluk düzeylerine etkisinin incelenmesi. Yayımlanmamış Yüksek Lisans Tezi. İstanbul: Gelişim Üniversitesi.

Baruönü, F, Ö. (2020). Covid-19 ve Türkiye'de Kısa Vadeli Tüketici Davranışına Yansıması. Yönetim, Ekonomi ve Pazarlama Araştırmaları Dergisi, 4(3), 152-168.

Birimoğlu-Okuyan, C., Bilgili, N., \& Mutlu, A. (2020). Factors affecting nursing students' intention to work as a geriatric nurse with older adults in Turkey: A cross-sectional study. Nurse Education Today, 95, 104563.

Coker, R. J., Hunter, B. M., Rudge, J. W., Liverani, M., \& Hanvoravongchai, P. (2011). Emerging Infectious Diseases in Southeast Asia: Regional Challenges to Control. Health in Southeast Asia 3 377(1). 599-609.

Comrey, A. L., \& Lee, H. B. (1992). A First Course in Factor Analysis. 2nd Edn. New Jersey: Hillsdale,

Çavmak, D., Çavmak, Ş., \& Söyler, S. (2020). A crosssectional examination of the effects of Covid-19 on Turkish community: An integrated perspective of social, economic and public health issues. Management in Health, 24(2). 8-13.

Çınar, İ. (2014). Ölüm Kaygısı ve Gösterişçi Tüketim Eğilimi. Iğdır Üniversitesi Sosyal Bilimler Dergisi, 5, 89-104.

Danışmaz, A.T., (2020). COVID-19 salgınının tüketicilerin online alışveriş tercihine etkisi. Sosyal Bilimler Araştırma Dergisi, 9 (2), s.83-90.

Durmuş, B., Yurtkoru, S. \& Çinko, M. (2013). Sosyal Bilimlerde SPPS'le Veri Analizi 5.Baskı. İstanbul: Beta Basım Yayın Dağıtım A.Ş.

Dündar, A. (2020). Ölüm kaygısının tüketici davranışları üzerindeki etkisi: Soğuk savaş döneminde ABD toplumu. Yayımlanmamış Yüksek Lisans Tezi. Ankara: Başkent Üniversitesi.

Elavarasan, R.M. ve Pugazhendhi, R., (2020), Restructured society and environment: A review on potential technological strategies to control the COVID-19 pandemic, Science of The Total Environment 725, 138858, s.1-18.

Erciş, A., Kotan, G. \& Türk, B. (2016). Ölüm Kaygısının Tüketici Tutumları Üzerindeki Etkileri. Journal of Suleyman Demirel University Institute of Social Sciences, 23(1). 107-134.

Fornell, C. \& Larcker, D. F. (1981). Evaluating Structural Equation Models with Unobservable Variables and Measurement Error. Journal of Marketing Research, 18(1), 39-50.

Goddard, E., (2020). The impact of COVID-19 on food retail and food service in Canada: Preliminary assessment. 
Canadian Journal of Agricultural Economics/Revue canadienne d'agroeconomie, s.1-5.

Greger, M. (2007). The Human/Animal Interface: Emergence and Resurgence of Zoonotic Infectious Diseases. Critical Reviews in Microbiology, 33(4), 243-299.

He, H., \& Harris, L., (2020). The Impact of Covid-19 Pandemic on Corporate Social Responsibility and Marketing Philosophy. Journal of Business Research 116, 176- 182.

Huang, C. C., Wang, Y. M., Wu, T. W., \& Wang, P. A. (2013). An Empirical Analysis of the Antecedents And Performance Consequences of Using The Moodle Platform. International Journal of Information and Education Technology, 3(2), 217.

İnce, M. \& Tor-Kadığlu, C . (2020). Tüketicilerin COVID19 (Korona) virüsüyle artan stoklama isteğinin online satın alma davranışına etkisi. OPUS Uluslararası Toplum Araştırmaları Dergisi, 16 (29), 126-156.

Knotek, E.S., Schoenle, R., Dietrich, A., Kuester, K., Müller, G., Myrseth, K.O.R., \& Weber, M., (2020). Consumers and COVID-19: A real-time survey. Economic Commentary, (08), 1-6.

Ladikli, N., Bahadır, E., Yumuşak, F. N., Akkuzu, H., Karaman, G., \& Türkkan, Z. (2020). Covid-19 korkusu ölçeği'nin Türkçe güvenirlik ve geçerlik çalışması. International Journal of Social Science, 3(2), 71-80.

Larson, L. R., \& Shin, H. (2018). Fear during natural disaster: 1ts impact on perceptions of shopping convenience and shopping behavior. Services Marketing Quarterly, 39(4), 293-309.

Mandel, N. \& Smeesters, D. (2008). The sweet escape: effects of mortality salience on consumption quantities for high-and low-self-esteem consumers. Journal of Consumer Research, 35(2), 309-323.

Meydan, C. H., \& Şeşen, H. (2011). Yapısal eşitlik modellemesi AMOS uygulamaları. Detay Yayınc1lık.

Nguyen, H.V., Tran, H.X., Van Huy, L., Nguyen, X.N., Do, M.T., ve Nguyen, N, (2020). Online book shopping in vietnam: the impact of the COVID-19 pandemic situation, Publishing Research Quarterly, s.1-9.

Nunnally, J.C. (1978). Psychometric Theory. 2nd edition New York.: McGraw-Hill.

Nunnualy, J.C., \& Bernstein, I. (1994). Psychometric Theory. 3rd edition. New York: McGraw-Hill.
Pett, M.A., Lackey, N.R., \& Sullivan, J. (2003). Making sense of factor analysis: the use of factor analysis for instrument development in healthcare research. SAGE. Publications, Thousand Oaks.

Richards, T.J. ve Rickard, B., (2020), “COVID-19 impact on fruit and vegetable markets", Canadian Journal of Agricultural Economics/Revue canadienne d'agroeconomie, s.1-6

Rio-Chanona, R.M, Mealy P., Pichler A, Lafond, F. \& Farmer D.F. (2020). Supply and demand shocks in the covid-19 pandemic: an industry and occupation perspective. COVID Economics Vetted and RealTime Papers, Centre for Economic Policy Research Press. 6: 65-103.

Stanciu, S., Radu, R.I., Sapira, V., ve Dumitrache, B., (2020). Consumer behavior in crisis situationsresearch on the effects of COVID-19 in Romania, Annals of Dunarea de Jos University of Galati, s.513

Temel, K. \& Ertin, H. (2020). 1918 grip pandemisi kıssasından COVID-19 pandemisine hisseler. Anadolu Kliniği Tip Bilimleri Dergisi, Cilt 25, (1). 63-78.

Tomás-Sábado, J. \& Gómez-Benito, J. (2005). Construction and Validation of the Death Anxiety Inventory (DAI). European Journal of Psychological Assessment, 21(2), 108.

Tomás-Sábado, J., Gómez-Benito, J., \& Limonero, J. T. (2005). The Death Anxiety Inventory: A Revision. Psychological Reports Journal, 97(3), 793796.

Urien, B. \& Kilbourne, W. (2008). On the Role of Materialism in the Relationship Between Death Anxiety and Quality of Life. ACR North American Advances. 35(1), 409-415.

Wen, J., Kozak, M., Yang, S., ve Liu, F., (2020). COVID19: Potential effects on Chinese citizens' lifestyle and travel. Tourism Review

Wu, T., Perrings, C., Kinzig, A., Collins, J. P., Minteer, B. A., \& Daszak, P. (2017). Economic growth, urbanization, globalization, and the risks of emerging infectious diseases in China: A Review. Ambio Journal, 46(1), 18-29.

Yurtsever, U. (2019). Ölüm kaygısının tüketicilerin sigorta tercihlerine etkisi: Kuşaklar arası bir karşılaştırma. Yayımlanmamış Yüksek Lisans Tezi. Muğla: Muğla S1tk1 Koçman Üniversitesi. 


\section{Extended Abstract}

Death anxiety is a factor that every person has and is a part of life. Due to the COVID-19 pandemic experienced all over the world, societies are financially and morally anxious. The resulting economic uncertainty causes consumers' distrust and anxiety about the economy and has a negative impact on their consumption intentions. The concept of death anxiety, which is often explored in sciences such as religion, philosophy and psychology is fairly new to marketing science.

It is thought that the moral risks perceived by consumers during the pandemic process can change their attitudes and behavior. The purpose of this research is to adapt the "Death Anxiety Scale" developed by Tomas-Sabao, Gomez-Benito and Limonero to the pandemic process and evaluate it in terms of consumer groups. With this adapted scale, the behaviors of consumers who feel death anxiety with the COVID-19 pandemic in 2020 become more understandable. In the study, death anxiety of consumers was explained, and the literature on consumer and death anxiety was included. Then, the method of the research was explained in detail, and information was given about the sample and data collection.

The sample of the study is composed of 386 consumers who live in Turkey and indicate that they do not leave the house unless they are obliged to go through the COVID-19 pandemic process, so who are in quarantine. The data of the study were collected through an online survey in MarchApril 2020. With this research, the measurement tool, consisting of 4 factors and 17 items, was adapted to the pandemic process and made available to researchers. It was calculated that the overall reliability value of the death anxiety scale used was 0.896 .

In this study, death anxiety felt by the consumers was evaluated in 4 dimensions.(External death anxiety, acceptance of death, the inevitability of death, thoughts about death). It has been predicted that the perceived death anxiety will differ according to the gender, age, income and education level of the participants. Considering the differences between groups, it is observed that female consumers are more concerned in all dimensions compared to men; consumers between the ages of 18-31 are more anxious than older consumers; it has been observed that lowincome consumers are more anxious than those with high income. Consumers with low education level compared to those with high education level; external death anxiety, acceptance of death and thoughts about death dimensions were found to be more anxious.

Many studies have been found investigating the impact of COVID-19 on; online purchases (Danışmaz, 2020); online book purchases (Nguyen, 2020); stocking and online purchases (İnce \& Tor-Kadığlu, 2020); technological strategies (Elavarasan \& Pugazhendhi, 2020); the fruit and vegetable market (Richards \& Rickard, 2020); economic and public health (Cavmak et al., 2020); corporate social responsibility (He \& Harris, 2020); consumers' lifestyles (Çakıroğlu et al., 2020); consumers' lifestyles and travels in China (Wen et al. 2020); retail food and catering service in Canada (Goddard, 2020). This study is important in terms of revealing the death anxiety felt by the consumers during the pandemic process. There are also many studies that have similar inferences with this study (Birimoğlu-Okuyan, et al., 2020; Stanciu et al., 2020; Ladikli, et al. 2020;).

When the results were examined, significant differences were determined in terms of gender, age, income and education level in the dimensions of external death anxiety, acceptance of death, thoughts about death and inevitability of death. If a sectoral proposal is required, it is recommended to increase technology-intensive services due to the death anxiety detected in consumers. It has been understood that consumers can efficiently receive distance education, perform online banking transactions, easily order online goods / services, and prefer channels with little personal contact. In this case, the companies in the marketing sector; it is recommended to focus on the use of artificial intelligence, drone use, $5 \mathrm{G}$ and smart applications, and robot systems. 
EK 1. Etik Kurul İzni

\section{ชิ}

TARSUS

TARTUS T.C.

tivituretrest

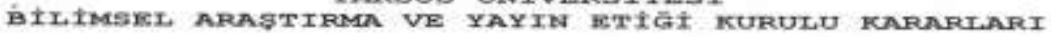

\begin{tabular}{|c|c|c|}
\hline Kafar Tarth1 & Toplanti Bayial & Karas sayial \\
\hline $05 / 03 / 2020$ & 02 & $2020 / 17-1$ \\
\hline
\end{tabular}

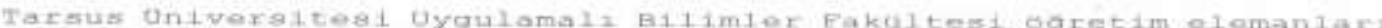
Prof.DE. Mehmet INCE 1 le Ats.GOx.Canau TOR KADIOGLU tarafindan

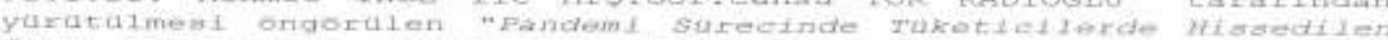
orum Kaygasman Demografik paktoriere Gore Degerlemdirilmosif

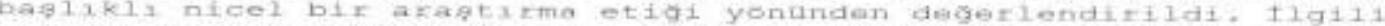
calimanin uygulamabilmeainin kabulune toplantiya katilanlarin oy birligi tie karar yerildi.

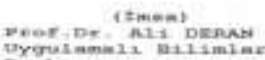

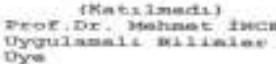

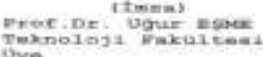

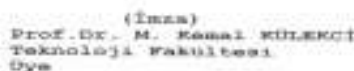

(Imasa)

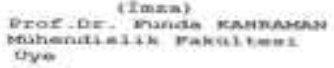

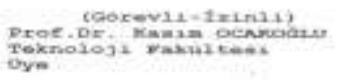

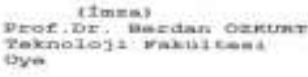

ASLI GIBRIDIR

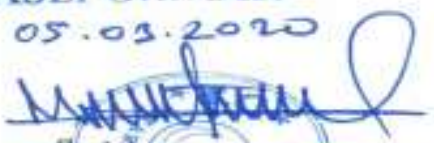

Pref fo Met

Gen Mehmetince

Geno seduntor $V$ 
EK 2.

\begin{tabular}{|c|c|c|c|}
\hline $\begin{array}{l}\text { I get upset when I am in a } \\
\text { cemetery }\end{array}$ & Bir mezarlığa gidince üzgün olurum & $\begin{array}{l}\text { Korona virüsten hayatını kaybedenleri } \\
\text { görünce üzülürüm. }\end{array}$ & DÖK \\
\hline $\begin{array}{l}\text { The certainty of death makes } \\
\text { life meaningless }\end{array}$ & Ölüm gerçeği hayatı anlamsız kılar & $\begin{array}{l}\text { Korona virüsün ölümcül olması hayatı } \\
\text { anlamsızlaştırır. }\end{array}$ & ÖK \\
\hline $\begin{array}{l}\text { It annoys me to hear about } \\
\text { death }\end{array}$ & $\begin{array}{l}\text { Ölüm hakkında duyduklarım beni } \\
\text { rahatsız eder }\end{array}$ & $\begin{array}{l}\text { Korona virüs hakkında duyduklarım beni } \\
\text { rahatsız eder }\end{array}$ & ÖK \\
\hline $\begin{array}{l}\text { I find it difficult to accept the } \\
\text { idea that it all finishes with } \\
\text { death }\end{array}$ & $\begin{array}{l}\text { Her şeyin ölümle biteceği fikrini } \\
\text { kabullenmekte zorlanırım }\end{array}$ & $\begin{array}{l}\text { Korona virüsün ölümcül olması fikrini } \\
\text { kabullenemem }\end{array}$ & KAÇ \\
\hline $\begin{array}{l}\text { I think I would be happier if I } \\
\text { ignored the fact that I have to } \\
\text { die }\end{array}$ & $\begin{array}{l}\text { Bir gün öleceğim gerçeğini göz ardı } \\
\text { ettiğimde daha mutlu olurdum }\end{array}$ & $\begin{array}{l}\text { Virüsün bulaşma riskini görmezden } \\
\text { geldiğimde daha mutlu olurum. }\end{array}$ & ÖK \\
\hline $\begin{array}{l}\text { I think I am more afraid of } \\
\text { death than most people }\end{array}$ & $\begin{array}{l}\text { Sanırım ölümden birçok insandan } \\
\text { daha fazla korkuyorum }\end{array}$ & $\begin{array}{l}\text { Korona virüsün bulaşıcılığından birçok } \\
\text { insana göre daha fazla korkarım }\end{array}$ & ÖK \\
\hline $\begin{array}{l}\text { I find it really difficult to accept } \\
\text { that I have to die }\end{array}$ & $\begin{array}{l}\text { Bir gün öleceğimi kabullenmek zor } \\
\text { geliyor }\end{array}$ & $\begin{array}{l}\text { Korona virüsünün ölümcül bir virüs olduğunu } \\
\text { kabullenmek zor gelir. }\end{array}$ & ÖK \\
\hline $\begin{array}{l}\text { I would never accept a job in a } \\
\text { funeral home }\end{array}$ & $\begin{array}{l}\text { Mezarlıkta çalışmayı asla kabul } \\
\text { etmem }\end{array}$ & $\begin{array}{l}\text { Virüs bulaşma riski olan bir yerde çalışmayı } \\
\text { asla kabul etmem. }\end{array}$ & DÖK \\
\hline $\begin{array}{l}\text { The idea that there is nothing } \\
\text { after death frightens me }\end{array}$ & $\begin{array}{l}\text { Ölümden sonra hiçbir şeyin } \\
\text { olmadığ fikri beni korkutur }\end{array}$ & $\begin{array}{l}\text { Virüsün aşısının olmaması fikri beni } \\
\text { korkutur. }\end{array}$ & KAÇ \\
\hline The idea of death troubles me. & Ölüm fikri beni rahatsız eder & $\begin{array}{l}\text { Virüsün bana bulaşması fikri beni rahatsız } \\
\text { eder. }\end{array}$ & KAÇ \\
\hline $\begin{array}{l}\text { I very often think about the } \\
\text { cause of my death. }\end{array}$ & $\begin{array}{l}\text { Ölüm sebebim hakkında çok sık } \\
\text { düşünürüm }\end{array}$ & $\begin{array}{l}\text { Virüsün bana bulaşabileceği yollar hakkında } \\
\text { çok sık düşünürüm. }\end{array}$ & ÖİD \\
\hline Coffins make me nervous & Tabut görünce gerginleşirim & $\begin{array}{l}\text { Virüsten hayatını kaybedenleri görmek beni } \\
\text { gerginleştirir. }\end{array}$ & DÖK \\
\hline $\begin{array}{l}\text { I am worried about what's after } \\
\text { death }\end{array}$ & $\begin{array}{l}\text { Ölümden sonra ne olduğu } \\
\text { konusunda endişelenirim }\end{array}$ & $\begin{array}{l}\text { Virüs kaptıktan sonra bana ne olacağ } 1 \\
\text { konusunda endişelenirim. }\end{array}$ & KAÇ \\
\hline $\begin{array}{l}\text { I often think I may have a } \\
\text { serious disease }\end{array}$ & $\begin{array}{l}\text { S1k s1k ciddi bir hastalığım } \\
\text { olabileceğini düşünürüm }\end{array}$ & $\begin{array}{l}\text { Korona virüs taşıyıcısı olabileceğimi çok sık } \\
\text { düşünürüm. }\end{array}$ & ÖİD \\
\hline $\begin{array}{l}\text { Dying is the worst thing that } \\
\text { could happen to me }\end{array}$ & $\begin{array}{l}\text { Ölmek başıma gelebilecek en kötü } \\
\text { şeydir }\end{array}$ & $\begin{array}{l}\text { Korona virüsün bana bulaşması başıma } \\
\text { gelebilecek en kötü şeydir. }\end{array}$ & ÖK \\
\hline $\begin{array}{l}\text { The sight of a corpse deeply } \\
\text { shocks me }\end{array}$ & $\begin{array}{l}\text { Bir cesedin görüntüsü beni derinden } \\
\text { sarsar }\end{array}$ & $\begin{array}{l}\text { Virüsten hayatını kaybedenleri görmek beni } \\
\text { derinden sarsar. }\end{array}$ & DÖK \\
\hline $\begin{array}{l}\text { I frequently think of my own } \\
\text { death }\end{array}$ & Bazen kendi ölümümü düşünürüm & $\begin{array}{l}\text { Bazen virüsün bana çoktan bulaştığını } \\
\text { düşünürüm. }\end{array}$ & ÖİD \\
\hline
\end{tabular}

